\title{
Emergy analysis of the wetland comprehensive development level
}

\author{
Xinjian Guan ${ }^{1, a}$, Wenkang Liu' ${ }^{2, b}$ and Xueyan $\mathrm{Qi}^{3, \mathrm{c}}$ \\ ${ }^{1,2}$ Institute of Water Conservancy and Environment, Zhengzhou University, Henan Zhengzhou \\ 450001, China \\ ${ }^{3}$ Yellow River Hydrological and Water Resources Bureau, Henan Zhengzhou 450003, China

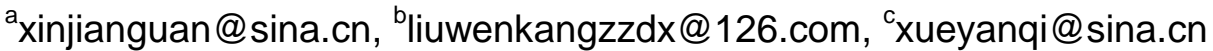

\begin{abstract}
Keywords: wetlands; wetland ecosystem; emergy theory; wetland comprehensive development level

Abstract. As the wetland ecosystem in the field of research is insufficient, this paper established Effect Evaluation Index System of comprehensive development level of wetlands based on their ecosystem functions and performance characteristics. The entropy method was used to determine the index weight, the set of integrated analysis was used to measure the level of development of wetlands, and the East Juyan Lake was used as a practical example. The results showed that comprehensive development level of East Juyan Lake wetland presented a trend of decreased first and then increased, However in the vertical perspective, the overall comprehensive development level of the wetland was low, which was consistent with theoretical study and system function evaluation of East Juyan Lake basin. This research has great significance to both improving the theoretical research in the field of wetlands and accelerating scientific understanding of the importance of delivering Heihe water to East Juyan Lake basin.
\end{abstract}

\section{Introduction}

With the development of social economy, the contribution of wetlands resources to human become increasingly prominent, and people are paying more and more attention to rational development and sustainable utilization of wetland resources. The State Council gave priority to "Wetland protection and rational utilization" in $<$ The Administrative Center for China's Agenda: $21>$ and $<$ China Biological Diversity Protection Action Plan> in 1994, and increased the area of wetland-related research investment. This will greatly promotes the development of the wetland ecological scholars' research activities, and the related research achievements of wetland also will be increased. But on the whole, wetland areas only focused on the value of the wetland ecological functions assessment[1],wetland dynamic analysis of landscape[2] pattern, research in wetland ecological fragility[3],wetland ecosystem health evaluation and so on[4].The evaluation tools are mostly according to the existing evaluation system with a unified measures to analyze development situation of the different wetland, and it can be said that the research range of the wetland field are more limited currently and the model building is not targeted. The impact of wetland on social-economic system is gradually increasing in the continuous development of social-economic, but the state of development of wetlands affected not only by their own system structure of wetland, but also by the level of social-economic development, the scale of wetland, geographical location and the social-economic development model of wetland and other various factors[5]. Thus we need to find a set of evaluation system in "tailored" aiming to wetland characteristics, and can comprehensively reflect the evaluation model of wetland development level from the perspective of ecology economy society. Energy analysis theory is an analytical method from the angle of ecological economics to analyze the system energy flow, storage and conversion features [6,7]. Energy conversion rate and Energy currency ratio are the tools which can conduct a conversion among material, energy and currency, which are the bridge linking social system, economic system and ecosystem [8], and the ideal tools to conduct ecological economic evaluation. In this paper, we took the emergy theory as a quantitative means. We took the East Juyan Lake as a practical example, combining self characteristics of the lake to establish an evaluation system. We also used set pair analysis to construct wetlands comprehensive 
development level evaluation model $[9,10]$.This paper tried to compensate the lack of wetlands research and enhance the knowledge and understanding of East Juyan Lake wetland.

\section{Methods}

Emergy Evaluation of Wetland Ecosystem Values. The paper quantitative studies the dynamic characteristics of the wetland ecosystem value from the perspective of the social-ecological-economic system by using emergy theory[11], and analyze the trends of system functional change in East Juyan Lake wetland since 1950s, providing data for further analysis of the comprehensive development level in the wetland.

Combining the performance results of wetlands' each function, and using the emergy equations, we can analyze the wetland emergy value of each function. The results are shown in Table 1.

- Water conservation value $=$ Storage Capacity $\times$ Energy Conversion Rate

-Fixing carbon and releasing oxygen value $=$ Fixed amount of $\mathrm{CO} 2 \times$ Emergy Conversion rate of $\mathrm{CO} 2+$ Release amount of $\mathrm{O} 2 \times$ Emergy Conversion Rate of $\mathrm{O} 2$

- Sand-fixing value $=$ Reduce the loss of volume $\times$ Soil nutrient content $(\%) \times$ Emergy Conversion Rate

-Maintenance of species diversity value $=$ Species of species $\times$ Wetland area $/$ Global area $\times$ Emergy Conversion Rate

- Cooling humidification value [12] = Potential evaporation $\times$ Evaporation $\times$ Wetland area $\times$ Density $\times$ Emergy Conversion Rate

-Production value of material $=$ Fish production $\times$ Emergy Transformation + Aquatic yield $\times$ Emergy Conversion Rate

- Research and Education value $=($ Academic achievement $\times 6+$ Report $\times 1) \times$ Emergy Conversion Rate

Table 1. Each stage Function value of East Juyan Lake wetland eco-environment system. [unit: sej]

\begin{tabular}{|c|c|c|c|c|c|}
\hline \multirow{2}{*}{\multicolumn{2}{|c|}{$\begin{array}{l}\text { development stages } \\
\text { wetland functions }\end{array}$}} & \multicolumn{2}{|c|}{ Atrophy period } & \multirow{2}{*}{ Dry period } & \multirow{2}{*}{$\begin{array}{l}\text { Ecological } \\
\text { recovery period }\end{array}$} \\
\hline & & $50 \mathrm{~s}$ & $80 \mathrm{~s}$ & & \\
\hline \multirow{6}{*}{$\begin{array}{l}\text { Ecological } \\
\text { value }\end{array}$} & Water conservation & $2.63 \mathrm{E}+21$ & $8.74 \mathrm{E}+19$ & $0.00 \mathrm{E}+00$ & $1.39 \mathrm{E}+20$ \\
\hline & $\begin{array}{l}\text { Carbon fixation and } \\
\text { oxygen release }\end{array}$ & $1.10 \mathrm{E}+16$ & $4.13 \mathrm{E}+15$ & $0.00 \mathrm{E}+00$ & $1.09 \mathrm{E}+16$ \\
\hline & $\begin{array}{l}\text { Windbreak and sand } \\
\text { fixation }\end{array}$ & $0.00 \mathrm{E}+00$ & $4.50 \mathrm{E}+18$ & $0.00 \mathrm{E}+00$ & $2.79 \mathrm{E}+18$ \\
\hline & $\begin{array}{l}\text { Maintenance of } \\
\text { biological diversity } \\
\text { Cooling }\end{array}$ & $3.39 \mathrm{E}+20$ & $1.69 \mathrm{E}+19$ & $1.69 \mathrm{E}+18$ & $2.60 \mathrm{E}+19$ \\
\hline & humidification & $8.73 \mathrm{E}+18$ & $2.90 \mathrm{E}+18$ & $0.00 \mathrm{E}+00$ & $4.62 \mathrm{E}+18$ \\
\hline & subtotal & $6.11 \mathrm{E}+21$ & $1.12 \mathrm{E}+20$ & $1.69 \mathrm{E}+18$ & $1.72 \mathrm{E}+20$ \\
\hline \multirow{3}{*}{$\begin{array}{l}\text { Economic } \\
\text { value }\end{array}$} & Aquatic & $2.35 \mathrm{E}+16$ & $8.81 \mathrm{E}+15$ & $0.00 \mathrm{E}+00$ & $2.27 \mathrm{E}+16$ \\
\hline & Fish products & $2.99 \mathrm{E}+18$ & $4.46 \mathrm{E}+17$ & $0.00 \mathrm{E}+00$ & $1.36 \mathrm{E}+18$ \\
\hline & subtotal & $3.01 \mathrm{E}+18$ & $4.55 \mathrm{E}+17$ & $0.00 \mathrm{E}+00$ & $1.39 \mathrm{E}+18$ \\
\hline Social value & $\begin{array}{l}\text { Research Education } \\
\text { Aesthetic Value }\end{array}$ & - & $2.51 \mathrm{E}+17$ & $7.93 \mathrm{E}+17$ & $\begin{array}{l}8.34 \mathrm{E}+17 \\
9.63 \mathrm{E}+18\end{array}$ \\
\hline & subtotal & - & $2.51 \mathrm{E}+17$ & $7.93 \mathrm{E}+17$ & $1.07 \mathrm{E}+19$ \\
\hline \multicolumn{2}{|c|}{ Emergy Summation } & $6.11 \mathrm{E}+21$ & $1.13 \mathrm{E}+20$ & $2.48 \mathrm{E}+18$ & $1.84 \mathrm{E}+20$ \\
\hline
\end{tabular}

As can be seen from Table 1, the emergy value of the ecological economic system of East Juyan Lake wetland in various stages was $6.11 \mathrm{E}+21 \mathrm{sej}, 1.13 \mathrm{E}+21 \mathrm{sej}, 2.48 \mathrm{E}+18 \mathrm{sej}$ and $1.84 \mathrm{E}+20 \mathrm{sej}$.From the point of the function value, the amount of emergy fluctuated the tendency of increasing after reducing, which is in accordance with the development process from shrinking period to dry period and then coming to ecological recovery period. From the lateral view, the ecological value of East Juyan Lake wetland in $1950 \mathrm{~s}-1080$ s constantly decreased from $6.11 \mathrm{E}+21$ sej to $1.12 \mathrm{E}+21$ sej, the ecological value had a significantly decrease. The wetland ecological environment quality constantly 
shrinked and the functions continuously degradated; In the period of dry, the wetland nearly completely disappeared, just leaving malnourished reeds and nearly dead plants, and the ecological value is only $1.69 \mathrm{E}+18 \mathrm{sej}$; After the diversion, the wetland ecological value increased to $1.72 \mathrm{E}+20 \mathrm{sej}$, $93.47 \%$ of the total value and became a major performance of the wetland system value. The economic value of the East Juyan Lake wetland also showed the same trend from increase to decrease. The East Juyan Lake wetland social value showed an increasing trend, which is mainly affected by the level of scientific research and the development of tourism industry. The wetland tourism began in the 1990s with a late start, although there were a great number of people traveled here in the historical period, the tourism resource has not been industrialized; After the East Juyan Lake wetland dried up, in order to further deepen the awareness and understanding of the East Juyan Lake, the targeted saving measures were developed, and there has a significant increase in wetland-related research activities compared to the period before the dry. The research results were a corresponding increase, and the social value of wetlands gradually appears.

Construction of Comprehensive Development Level Evaluation Model of Wetland.The construction of comprehensive development level evaluation model of wetland mainly based on the following aspects: On the basis of functional characteristics of the research region to establish the evaluation index system of the model; Putting the emergy theory as quantify tools to assess the function value of wetland; Putting correlation as indicator to characterize the research object's comprehensive level relative to the comprehensive development of wetlands in our country. In this paper, we took East Juyan Lake as an example to explain the comprehensive development level evaluation model of wetlands and also the process of building. In order to reflect the actual situation of various stages of development level of the East Juyan Lake wetland, we took ecological economic system value evaluation index system of East Juyan Lake wetland for criteria, and took emergy value of the coefficient for evaluation factor, according to 16 distinctive ecological economic system development of wetlands which are under the different climate conditions such as Arid region, Humid region, Cold region and so on, to build optimal set and worst set. We use set pair analysis to have a systematic analysis for comprehensive development level in wetland of East Juyan Lake. The following are the specific steps:

Construction of the set. We collected and analyzed Dongting Lake, Poyang Lake and other 16 wetlands' production related material, the ecosystem services value and other information, and calculated the results according to emergy quantized methods of various functions in East Juyan Lake wetland $[13,14]$.To reduce the uncertainty caused by the size of the wetland, the social-economic development and other factors, we take emergy value coefficient for quantized unit. According to the East Juyan Lake wetland ecological system evaluation, and we select each index sets' minimum for worst set and maximum for optimal set in 16 wetlands, and take it as evaluation index sets of set pair analyze, the results are shown in Table 2.

Table 2. The best set and the worst set statistics table. [unit: sej/km2]

\begin{tabular}{|c|c|c|c|c|c|c|c|}
\hline Items & Aquatic & $\begin{array}{l}\text { Aquatic } \\
\text { products }\end{array}$ & $\begin{array}{l}\text { Water } \\
\text { conservation }\end{array}$ & $\begin{array}{l}\text { Species } \\
\text { diversity }\end{array}$ & $\begin{array}{ll}\text { Carbon } & \text { fixation } \\
\text { and } & \text { oxygen } \\
\text { release } & \\
\end{array}$ & $\begin{array}{l}\text { Research } \\
\text { education }\end{array}$ & $\begin{array}{l}\text { Cooling } \\
\text { humidification }\end{array}$ \\
\hline Worst sets & $1.8 \mathrm{E}+14$ & $1.4 \mathrm{E}+16$ & $2.0 \mathrm{E}+17$ & $5.1 \mathrm{E}+18$ & $1.9 \mathrm{E}+15$ & $2.8 \mathrm{E}+14$ & $2.5 \mathrm{E}+16$ \\
\hline Optimal sets & $3.8 \mathrm{E}+16$ & $3.4 \mathrm{E}+20$ & $2.6 \mathrm{E}+19$ & $7.2 \mathrm{E}+18$ & $2.5 \mathrm{E}+17$ & $5.3 \mathrm{E}+17$ & $2.3 \mathrm{E}+17$ \\
\hline
\end{tabular}

For the evaluation of wetland aesthetic, different wetlands have different evaluation methods.But Shadow project method, Travel Cost Method or Benefit Reference Method were used more, the evaluation results of these methods are susceptible to external factors' influence, such as local social economic development, wetlands geographical location, transportation development etc, and the evaluation results often can't reflect the value of wetlands in truly and objectively; For the sand-fixing function of East Juyan Lake, many wetlands lack of it or its functional effect performed not obvious, so it is easy to be ignored in the evaluation what will result that information in this aspect is difficult to collect. Given these two reasons, in order to reduce the uncertainty of evaluation factors, the value of 
the wetland aesthetic and the sand-fixing will not be analyzed when we conduct comprehensive evaluation of the East Juyan Lake wetland.

Calculation of the same degree and different degree. Using the Eq.1 and Eq.2 of the set pair analysis to calculate the same degree and different degree of each measured value in East Juyan Lake, which the equation is about the same degree and different degree of the set pair, the results are shown in Table 3.

$$
\begin{aligned}
& a_{i j}=\frac{x_{i j}}{u_{j}+v_{j}} \\
& c_{i j}=\frac{u_{j} v_{j}}{\left(u_{j}+v_{j}\right) x_{i j}}
\end{aligned}
$$

Where, $a_{i j}$ is the index value for point $j$ in measured value $i$; $u_{j}$ is the optimal value for index $j$ in the evaluation index set, $\mathrm{v}_{\mathrm{j}}$ is the worst value for index $\mathrm{j}$ in the evaluation index set.

\begin{tabular}{|c|c|c|c|c|c|c|c|c|}
\hline \multirow[b]{2}{*}{ Items Indexes } & \multicolumn{4}{|c|}{ Identical degree } & \multicolumn{4}{|c|}{ Difference degree } \\
\hline & $50 \mathrm{~s}$ & $80 \mathrm{~s}$ & $\begin{array}{l}\text { Dry } \\
\text { period }\end{array}$ & $\begin{array}{l}\text { Recovery } \\
\text { period }\end{array}$ & $50 \mathrm{~s}$ & $80 \mathrm{~s}$ & Dry period & $\begin{array}{l}\text { Recovery } \\
\text { period }\end{array}$ \\
\hline Aquatic & 0.0089 & 0.0100 & 0.0000 & 0.0129 & 0.5309 & 0.4714 & - & 0.3668 \\
\hline $\begin{array}{l}\text { Aquatic } \\
\text { products }\end{array}$ & 0.0001 & 0.0001 & 0.0000 & 0.0001 & 0.3221 & 0.7187 & - & 0.4725 \\
\hline $\begin{array}{l}\text { Water } \\
\text { conservation }\end{array}$ & 1.4145 & 0.1412 & 0.0000 & 0.1120 & 0.0052 & 0.0519 & - & 0.0655 \\
\hline $\begin{array}{l}\text { Species } \\
\text { diversity }\end{array}$ & 0.3926 & 0.0588 & 0.0029 & 0.0451 & 0.6178 & 4.1246 & 82.6874 & 5.3747 \\
\hline $\begin{array}{l}\text { Carbon } \\
\text { fixation and } \\
\text { oxygen release }\end{array}$ & 0.0006 & 0.0007 & 0.0000 & 0.0009 & 11.9408 & 10.5861 & - & 8.0410 \\
\hline $\begin{array}{l}\text { Research } \\
\text { education }\end{array}$ & 0.0000 & 0.0203 & 0.0320 & 0.0337 & 0.0000 & 0.0259 & 0.0165 & 0.0157 \\
\hline $\begin{array}{l}\text { Cooling } \\
\text { humidification }\end{array}$ & 0.4811 & 0.4802 & 0.0000 & 0.3816 & 0.1796 & 0.1799 & - & 0.2264 \\
\hline
\end{tabular}

Table 3. The statistical table of the East Juyan Lake wetland same and difference index.

Determining the weights. Each index weight was determined by entropy method. According to the dispersion degree of evaluation indexes to measure index weight objective, the greater degree of dispersion, the greater impacts to the value of the system service function. Entropy method is a weighting method which is more objective than Analytic Hierarchy Process, and it has a wide range of applications in statistics [15]. According to the amount of emergy of each function value in different stages of East Juyan Lake, use the equations of entropy method to determine the weight of each index, the results are shown in Table 4.

Entropy method determines the index weights:

Assuming there are $m$ observed values and $n$ indexes, $x_{i j}$ is the index value for point $\mathrm{j}$ in observed value i. $(i=1,2, \ldots, m ; j=1,2, \ldots, n)$

(1)Non-negative processing of data

$$
x_{i j}=\frac{x_{i j}-\min \left(\mathrm{x}_{1 j}, \mathrm{x}_{2 j}, \cdots, \mathrm{x}_{n j}\right)}{\max \left(\mathrm{x}_{1 j}, \mathrm{x}_{2 j}, \cdots, \mathrm{x}_{n j}\right)-\min \left(\mathrm{x}_{1 j}, \mathrm{x}_{2 j}, \cdots, \mathrm{x}_{n j}\right)}+1
$$

(2)Calculating the proportion of observed value for point $i$ in the index value $j$

$$
P_{i j}=x_{i j} / \sum_{i=1}^{m} x_{i j}
$$


(3) Calculating the entropy index of item $\mathrm{j}$

$$
e_{j}=-\frac{1}{\ln m} \sum_{i=1}^{m}\left(\mathrm{p}_{i j} \times \ln \mathrm{p}_{i j}\right)
$$

(4) The index weights of item $\mathrm{j}$

$$
w_{j}=\left(1-\mathrm{e}_{j}\right) / \sum_{i=1}^{m}\left(1-\mathrm{e}_{i}\right)
$$

\begin{tabular}{|c|c|c|c|c|c|c|c|c|}
\hline Indexes & Aquatic & $\begin{array}{l}\text { Aquatic } \\
\text { products }\end{array}$ & $\begin{array}{l}\text { water } \\
\text { conservation }\end{array}$ & $\begin{array}{l}\text { Species } \\
\text { diversity }\end{array}$ & $\begin{array}{l}\text { Carbon } \\
\text { fixation } \\
\text { and } \\
\text { oxygen } \\
\text { release }\end{array}$ & $\begin{array}{l}\text { Research } \\
\text { education }\end{array}$ & $\begin{array}{l}\text { Cooling } \\
\text { humidification }\end{array}$ & Total \\
\hline Weights & 0.1321 & 0.1303 & 0.1796 & 0.1743 & 0.1346 & 0.1390 & 0.1101 & 1.000 \\
\hline
\end{tabular}

Table 4. The statistical table of the East Juyan Lake wetland each evaluation index weight value.

Calculation of correlation degree. According to the equation of correlation in set pair analysis, we analyzed development level of various stages of East Juyan Lake wetland. Correlation refers to the relative closeness of the index value and the optimal set. The greater the correlation, the higher the development level of wetlands and the more stable of the system structure. Eq.3 and Eq.4 were used to calculate the average of the sameness degree and the difference degree in each development period of the wetland. Then, Eq.5 was used to calculate the correlation in each period of the wetlands.

$$
\begin{aligned}
& a_{i}=\sum_{i=1}^{n} w_{j} c_{i j} . \\
& c_{i}=\sum_{i=1}^{n} w_{j} c_{i j} . \\
& c_{i}=\sum_{i=1}^{n} w_{j} c_{i j} .
\end{aligned}
$$

The calculation results show that the correlation degree of wetland in each period as follows: the correlation degree is 0.1693 in $50 \mathrm{~s}$, while the correlation degree is 0.1693 in $80 \mathrm{~s}$; the correlation degree is 0.0003 in dry period, while the correlation degree is 0.0341 in recovery period.

Analysis of the result. It can be seen from the changes of each period comprehensive development level in East Juyan Lake wetland: The East Juyan Lake had beautiful scenery and rich products in history. Since 50s, with the decrease of the amount of water, overgrazing, wantonly exploitation of wetland resources, and the wetland vegetation began to be destroyed, leading to the shrink of the wetland area year by year and the gradually subside of the wetland function. As can be seen from the Table 4, the correlation of East Juyan Lake reduced from 0.1693 to 0.0382 in 50 s to 80 s, the comprehensive development level of wetland decreased significantly. In the 80s,agricultural development in the upper reached of the Heihe river tended to be stable and the amount of interception of water resource in Heihe river tended to reduce, but the primary productivity of East Juyan Lake wetland had been seriously damaged, and its species diversity had been reduced, the water quality became salinated, and the extend of the damage was beyond self-repair capacity of wetland systems, resulted in the decrease of comprehensive development level of wetlands and its correlation is only 0.0382.The decrease of wetland area in East Juyan Lake further exacerbated the loss of soil and accelerated the process of desertification. 'Sand from Ejin', Ejin became one of China's four major source of desert area. The State Department began to implement water resources unified management planning of Hehei river basin in 1998, and the East Juyan Lake realized the first water delivery in 2002. After the diversion, the correlation of the East Juyan Lake wetland rose to 0.034, which 
indicated that the wetland conditions have improved under the implementation of water diversion plan that restore some wetland area, but compared with other wetlands in our country, the East Juyan Lake comprehensive level was still low. It illustrated that the wetland structure is not fully restored, and the ecological economic system has a poor stability and strongly vulnerability. As a result of the repair function of the ecological economy system itself has a lag, we suggest strengthening artificial measures, combining with rational, scientific and efficient management tools for the early realization of the rippling blue waves in East Juyan Lake.

\section{Conclusions}

The practice showed that, use the above methods to conduct more comprehensively and objectively evaluate for wetland of East Juyan Lake's comprehensive development level, the results of evaluation were more in line with the practical of the research area's dynamic changes and the evaluate method has scientific and feasibility. This research provided a quantitative evaluation method to understand the level of development of wetland, which could made people have a more intuitive understanding about the actual development of wetland, the current situation and changing character of regional wetland ecological resources system.

The comprehension development level of wetland of East Juyan Lake and the social-economic development model in Heihe River were closely related to human interference. The East Juyan Lake wetland gone through repeatedly from inputs to dry with the strong development of agricultural production in midstream and wanton exploitation of water resources. Coupled with the impact of local harsh natural climate conditions, and the comprehensive development level had a sharp decline. Especially during in 1950s to 1980s, the structure and function of wetland ecological economy system severely depredated, and the system's functional value significantly decreased. Under the influence of Heihe water's diversion plan, the comprehensive development level of wetland began to rise. As it can be seen, import water is the key to the survival of East Juyan Lake.

The East Juyan Lake is in the recovery stage currently. The comprehensive development level and system function have significantly improved trend, but if not strengthen the protection and carry out effective control measures, we will face the possibility of dying again. Therefore, it is recommended that under the basic premise of protecting the wetland of East Juyan Lake, we should increase wetland investment and strengthen artificial measures, and conduct more effective protection aimed at wetland against dominant factors in the East Juyan Lake wetland.

\section{Acknowledgements}

This work was financially supported by the National Natural Science Foundation of China (51479180). The authors would also like to thank the support of College of Water Conservancy and Environment in Zhengzhou University.

\section{References}

[1] Lijuan Zhang, Xinsheng Zhao: Researches on the emergy analysis of Poyanghu wetland[J]. Acta Ecological Sinica, 2004, 24(7):1480-1485. In Chinese.

[2] Chunling Liang: Researches on the ecosystem structure, function and service value of Nansi Lake wetland [D]. Shandong Normal University (2010). In Chinese.

[3] Xiang Bai: Researches on the driving mechanism and ecological fragility of Ebinur Lake wetland [D]. East China Normal University (2010). In Chinese.

[4] Weiguo Jiang: Evaluation of wetland ecosystem health based on RS and GIS: A case of Panjin city, Liaohe Delta [D].Nanjing Normal University (2003). In Chinese. 
[5] Hongkai Li: Researches on ecological security assessment and restoration of Xianghai Wetland [D].Northeast Normal University (2002). In Chinese.

[6] Dan Chen, Jing Chen, Zhuwu Lv,et al: A Quantitative Analysis Method in Water Sciences Research:Emergy Theory and Method[J].Journal of China Three Gorges Univ.(Nature Sciences),2008,02(30):1-5. In Chinese.

[7] M.T. Brown, S. Ulgiati Energy quality, emergy, and transformity: H.T Odum's contributions to quantifying and understanding systems [J].Ecological Modelling, 2004, 178(1-2):201-213.

[8] Shengfang Lan, Pei Qin, Hongfang Lu: Emergy analysis of eco-economic system [M].Beijing: Chemical Industry Press (2002). In Chinese.

[9] Li Chen, Er Yang, Li Li, et al: The ecological function and value of East Juyan Lake wetland [J].Yellow River, 2011, 33(2):84-85. In Chinese.

[10] Richard J T, Klein, Robert J, et al: Assessment of Coastal Vulnerability to Climate Change [J].Ambio A Journal of the Human Environment, 1999, 28(2):182-187.

[11] Simpson R D: Economic analysis and ecosystems: Some concept s and issues [J]. Ecological Applications, 1998, 8(2): 342-349.

[12] Cuimei Lv: Energy Research for Ecological Economic Value of Regional Water Resource [D].Zhengzhou University (2009). In Chinese.

[13] Dan Chen, Jing Chen, Zhaohui Luo: Emergy Evaluation of the Natural Value of Water Resources in Chinese Rivers [J].Environmental Management, 2009, 44: 288-297.

[14] H. T.Odum, Nils Peterson: Simulation and evaluation with energy systems blocks [J].Ecological Modeling, 1996, 93(1-3):155-173.

[15] Xingjun Li, Chunwu Yin: Country Water Conservancy Construction Performance Evaluate Based on Entropy [J]. Journal of Anhui Agricultural Sciences, 2011, 39(27):16712-16713. In Chinese. 